\title{
Capillary blood glucose monitoring, in-patient hypoglycaemia and quality of care
}

\author{
GREGORY C JONES, ${ }^{1}$ COLIN G PERRY, ${ }^{2}$ ANDREW MONAGHAN, ${ }^{3}$ BRIAN KENNON, ${ }^{4}$ \\ CHRISTOPHER AR SAINSBURY ${ }^{1}$
}

\begin{abstract}
Aims: Hypoglycaemia confers excess morbidity and mortality. UK guidelines recommend capillary blood glucose (CBG) measurement is repeated 15 minutes following identification and treatment of CBG $<4 \mathrm{mmol} / \mathrm{L}$. We assessed adherence to this guidance, influence of initial CBG on time to repeat (TTR), and the impact of a quality improvement intervention on TTR.

Methods: We identified CBG readings (Abbott-PrecisionWeb) of 18,118 inpatients with recorded hypoglycaemic CBG between January 2009 and September 2013. TTR and associations with initial CBG were investigated. A single ward was targeted with an intervention (National Health Service Scotland Quality Improvement Hub ThinkGlucose pilot) during 2012. TTR was identified and compared before, during and after intervention.

Results: Of 90,935 CBGs $<4 \mathrm{mmol} / \mathrm{L}, 4.4 \%$ had no recorded repeat CBG. Of the 83,484 repeated CBGs, median TTR was 80 minutes, with $8.9 \%$ repeated within 15 minutes and only $42.2 \%$ within 60 minutes. TTR was proportional to initial CBG with median 22 minutes (IQR 10-47) for initial CBG 1-1.9 mmol/L, median 48 minutes (IQR 24-104) for 2-2.9 mmol/L, median 112 minutes (IQR 52-309) for 3-3.9 $\mathrm{mmol} / \mathrm{L}(\mathrm{p}=0.05)$. On the vascular unit, TTR improved post intervention from a median 77 minutes (IQR 37-281, $\mathrm{n}=843$ ) to 29 minutes (IQR 19-55, $\mathrm{n}=1041$ ), and improvement persisted with median 20 minutes (IQR 15-28, $\mathrm{n}=\mathbf{2 6 8}$ ) in the nine months after the project ended.

Conclusions: TTR is a marker of treatment quality in hypoglycaemia and is suboptimal. TTR reduces with worsening initial degree of hypoglycaemia. We have shown that a quality improvement package can produce sustained reduction of TTR. Br J Diabetes Vasc Dis 2015;15:24-26
\end{abstract}

Department of Diabetes, Gartnavel General Hospital, Glasgow, G11 OYN, UK

2 NHS Scotland Quality Improvement Hub, Gyle Square, 1 South Gyle Crescent, Edinburgh, EH12 9EB, UK.

3 Vascular Surgical Unit, Western Infirmary, Glasgow, G11 6NT, UK.

${ }^{4}$ Department of Diabetes, Southern General Hospital, Glasgow, G51 4TF, UK.

Address for correspondence: Dr Gregory C Jones Department of Diabetes, Gartnavel General Hospital, Glasgow, G11 OYN, UK

Tel: +44 (0)1412113259

E-mail: g.jones3@nhs.net

http://dx.doi.org/10.15277/bjdvd.2014.041

\author{
Abbreviations and acronyms \\ CBG capillary blood glucose \\ IQR inter-quartile range \\ TTR time to repeat
}

Key words: diabetic ketoacidosis, Joint British Diabetes Society, diabetes mellitus, in-patient care

\section{Introduction}

In hospitalised patients with diabetes, hypoglycaemia is common with a reported frequency of 3.3-5.7\%.1-4 In the UK National Diabetes Inpatient Audit, hypoglycaemia occurred in $23.4 \%$ of inpatients with diabetes and $2.2 \%$ of these patients required parenteral glucose or glucagon. ${ }^{5}$ The frequency and severity of hypoglycaemia has been associated with an increase in pre- and post-discharge mortality and length of admission. ${ }^{6,7}$ Even in patients without diabetes, hypoglycaemia on hospital admission has been linked with a significant increase in inpatient mortality and bed occupancy. ${ }^{8}$ Patients experiencing hypoglycaemia (blood glucose $<4 \mathrm{mmol} / \mathrm{L}$ ) require prompt action with administration of rapidacting carbohydrate or glucagon followed by assessment of response to treatment by repeat blood glucose measurement. The Joint British Diabetes Societies inpatient care guidelines for the treatment of hypoglycaemia recommend that, following treatment of hypoglycaemia, CBG is repeated at between 10-15 minutes to ensure successful treatment. ${ }^{9}$ This timescale for repeating CBG is also recommended by the American Diabetes Association for all episodes of hypoglycaemia ( $<70 \mathrm{mg} / \mathrm{dL}$ [3.9 mmo//L]) occurring in patients with diabetes. ${ }^{10}$

We assessed adherence to this guidance and the influence of an intervention (National Health Service Scotland Quality Improvement Hub ThinkGlucose pilot) attempting to improve response time.

\section{Methods}

Capillary blood glucose data were extracted from the Abbott Precision Webb system (Abbott, UK). Whole-hospital data were included from eight acute hospitals and associated units within Greater Glasgow and Clyde Health Board (Gartnavel General Hospital, Western Infirmary, Glasgow Royal Infirmary, Victoria Infirmary, Southern General Hospital, Royal Alexandra Hospital, Inverclyde Hospital and Vale of Leven Hospital) between Jan 1 2008 and May 1 2013. Data available from the system included unique patient identifier, patient location, test date and time and CBG.

For the whole data set we assessed our adherence with 
standard of treatment of hypoglycaemia by examining the time to repeat CBG testing following each documented measurement in the hypoglycaemic range $(<4 \mathrm{mmol} / \mathrm{L})$.

In one clinical area (a 43-bed regional vascular unit in Western Infirmary Hospital Glasgow) we examined the effect of a pilot intervention (NHS Scotland Quality Improvement Hub ThinkGlucose pilot) on time to repeat CBG following hypoglycaemia. The Quality Improvement Hub is a national collaboration among health boards and Scottish Government Health Directorates which aims to support NHS boards with implementation of the Healthcare Quality Strategy, ${ }^{11}$ while licences for Think Glucose were purchased from the NHS Institute for Innovation and Improvement. Time to repeat CBG was measured for the 14 months prior to the intervention, 12 months of the intervention and nine months following cessation of the pilot study period. The intervention involved group education of all ward staff on in-patient diabetes management, introduction of a "hypo box" with associated treatment algorithm, physical resources aimed at highlighting patients with diabetes to ward staff (magnets for white boards and stickers for charts) and a decision support tool to prompt appropriate expert review. ${ }^{12}$

\section{Results}

From a total of 3,345,241 CBG measurements, 90,935 (2.72\%) were <4 $\mathrm{mmol} / \mathrm{L}$. Of these hypoglycaemic measurements, 4,046 (4.4\%) had no recorded repeat $C B G$ during admission and $91.8 \%$ did not meet guideline recommendations of time to repeat (TTR) of $<15$ minutes. Of the 83,484 who had repeat measurement, median TTR was 80 minutes (IQR 36-249), with 7,451 (8.9\%) repeated within 15 minutes and only 35,264 (42.2\%) within 60 minutes. TTR was proportional to initial CBG with median 22 minutes (IQR 10-47) for initial CBG 1.0-1.9 mmol/L, median 48 minutes (IQR 24-104) for 2.0-2.9 mmol/L, median 112 minutes (IQR 52-309) for 3.0-3.9 $\mathrm{mmol} / \mathrm{L}$. When the response time was compared per 0.1 $\mathrm{mmol} / \mathrm{L}$, the median drop in median response time was three minutes (IQR 1-5), with the largest single drop a reduction of 28 minutes in median response time between index CBG of 3.0 and $2.9 \mathrm{mmol} / \mathrm{L}$ (Figure 1). On the vascular unit, TTR improved from
Figure 1. Influence of initial $C B G$ value on time to repeat $C B G$

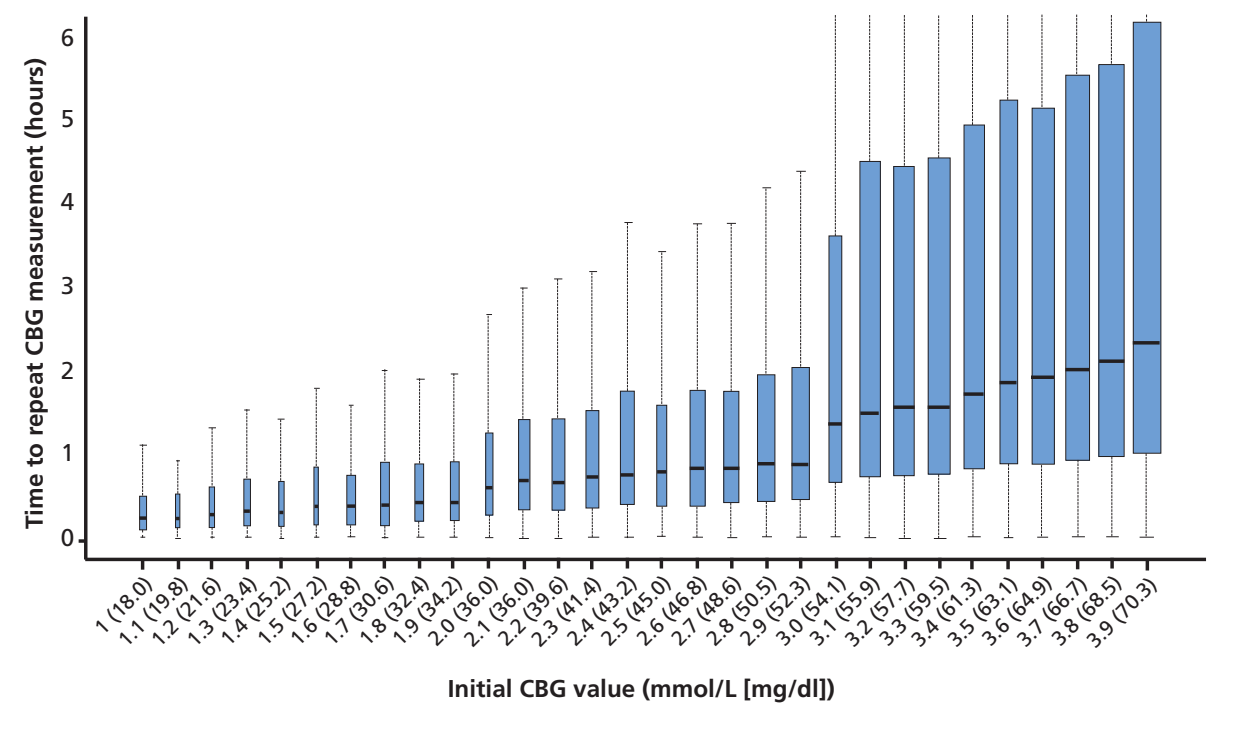

Figure 2. Time to repeat CBG per month, following CBG $<4 \mathrm{mmol} / \mathrm{l}(72 \mathrm{mg} / \mathrm{dl})$

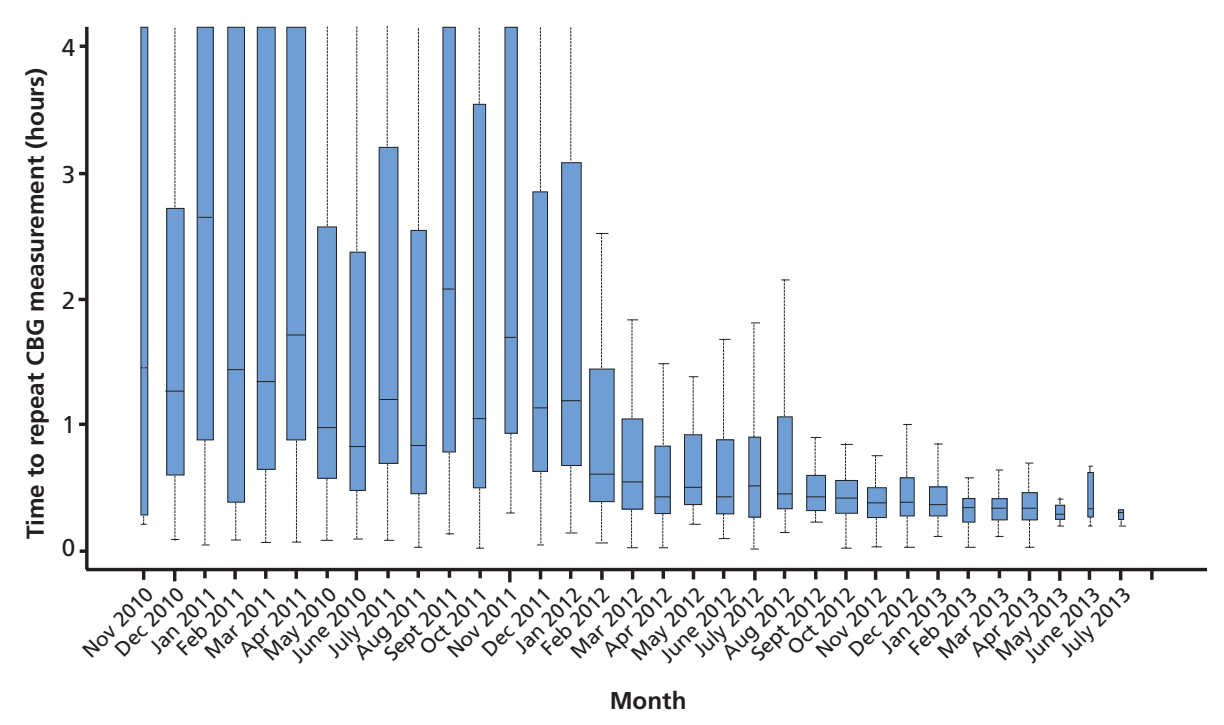


majority of cases, with less than $10 \%$ of hypoglycaemic episodes being retested within the recommended 15 minutes suggested by guidelines.., 10 Whilst 15 minutes could be considered a very stringent and perhaps aspirational target for repeat testing, it should be noted that only $42.2 \%$ of hypoglycaemic episodes were retested by 60 minutes. In some of these cases it is possible that retesting was not done on clinical grounds such as withdrawal of active treatment and end of life care. However the fact that the initial CBG has been tested would suggest that some active treatment was considered appropriate. We note that some hypoglycaemic episodes may have been adequately treated clinically but without repeat CBG measurement. Even if this is indeed the case, this would be against recommendations and would be difficult to justify in the event of a poor clinical outcome such as a fall, seizure or death following the initial recorded low CBG.

It is likely that a number of the hypoglycaemic CBG repeat results are in the same individual patients. We do not believe that this is reassuring as, even if the hypoglycaemic CBG is a recurrence or repeat after unsuccessful treatment of hypoglycaemia, it still should be treated independently and the response to that treatment needs to be checked by again repeating CBG testing.

It is notable that in the larger data set TTR decreased with magnitude of hypoglycaemia, suggesting that ward staff recognise that lower CBG levels are potentially more harmful. ${ }^{6} \mathrm{~A}$ larger 'step down' in response time is seen when CBG is below $3 \mathrm{mmol} / \mathrm{L}$ (54 mg/dL), indicating that whole numbers disproportionally influence the perception of severity of hypoglycaemia. We would expect that, where $\mathrm{mg} / \mathrm{dl}$ units are used, such a step in response may occur at terminal digits such as between 50 and $49 \mathrm{mg} / \mathrm{dL}$. It could be argued that CBG retesting is not meeting the target as health care staff have a justifiable perception that CBG results between 3 and $4 \mathrm{mmol} / \mathrm{L}$ are unlikely to be harmful, particularly in patients who may not be on insulin. Even if this were accepted, $2.1 \%$ of $C B G$ results $<3 \mathrm{mmol} / \mathrm{L}$ were never retested and only $17.0 \%$ were retested by 15 minutes and $61.5 \%$ by one hour, which is without doubt a concerning finding.

We have shown that a quality improvement intervention (National Health Service Scotland Quality Improvement Hub ThinkGlucose pilot) can have a measurable, pronounced and sustained impact on TTR CBG on a surgical unit. Whilst timely TTR of $C B G$ in hypoglycaemia does not prove alone that hypoglycaemia has been adequately treated, it at least allows for assessment of success in bringing glucose into the normal range. Despite the intervention on the described unit and the subsequent sustained improvement, still only $25 \%$ of hypoglycaemia episodes are having CBG repeated within the recommended time period of 15 minutes, suggesting there is still some way to go in reaching the desired standard of care.

TTR appears to be a useful marker of quality of treatment of hypoglycaemia in in-patients and can be used as an audit measure for assessing staff training and the impact of interventions aimed at service improvement.

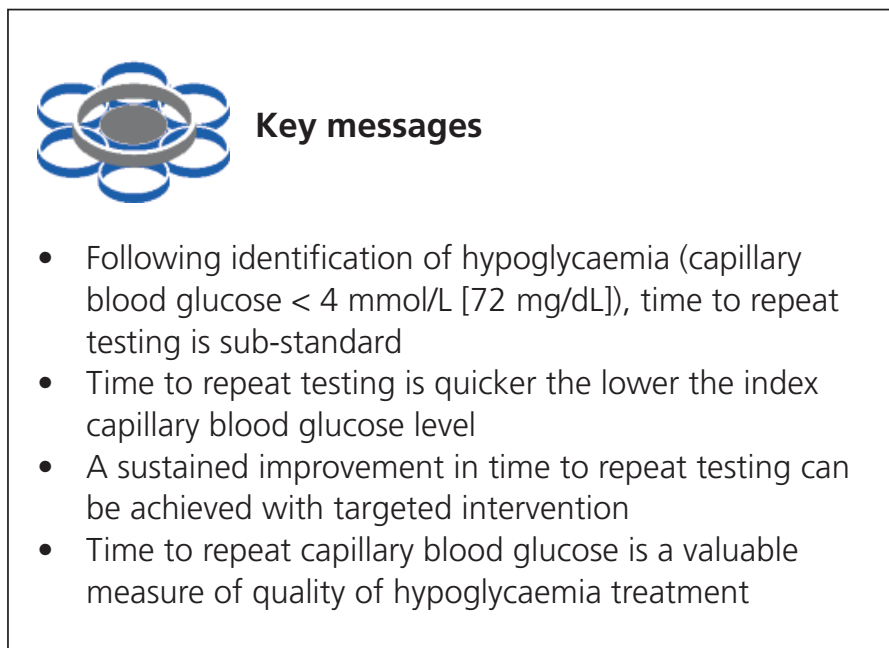

\section{Conflict of interest None}

Funding The NHS Scotland pilot of Think Glucose was funded by the NHS Scotland Quality Improvement Hub.

\section{References}

1. Swanson CM, Potter DJ, Kongable GL, et al. Update on inpatient glycaemic control in hospital in the United States. Endo Pract 2011;17: 85361. http://dx.doi.org/10.4158/EP11042.OR

2. Jones GC, Casey H, Perry CG, et al. Trends in recorded capillary blood glucose and hypoglycaemia in hospitalised patients with diabetes. Diabetes Res Clin Pract 2014;104:79-83. http://dx.doi.org/10.1016/j.diabres.2014.01.021

3. Bersoux S, Cook CB, Kongable GL et al. Trends in glycemic control over a 2-year period in US hospitals. J Hosp Med 2013;8:121-12. http://dx.doi.org/10.1002/jhm.1997

4. Kerry C, Mitchell S, Sharma S et al. Diurnal temporal patterns of hypoglycaemia in hospitalized people may reveal potentially correctable factors. Diabet Med 2013;30:1403-06. http://dx. doi.org/10.1111/dme.12256

5. National Diabetes Inpatient Audit 2012. Published March 2013. Available at http://www.hscic.gov.uk/. (Accessed 1 Feb 2014).

6. Turchin A, Matheny ME, Shubina M et al. Hypoglycemia and clinical outcomes in patients with diabetes hospitalized in the general ward. Diabetes Care 2009;32:1153-7. http://dx.doi.org/10.2337/dc08-2127

7. Nirantharakumar K, Marshall T, Kennedy A et al. Hypoglycaemia is associated with increased length of stay and mortality in people with diabetes who are hospitalized. Diabet Med 2012;29:445-8. http://dx.doi.org/10.1111/dme.12002

8. Tan HK, Flannagan D. The impact of hypoglycaemia on patients admitted to hospital with medical emergencies. Diabet Med 2013;30:574-80. http://dx.doi.org/10.1111/dme.12123

9. Joint British Diabetes Societies Inpatient Care Group. The Hospital Management of Hypoglycaemia in Adults with Diabetes Mellitus (March 2010). Available at http://www. diabetes.org.uk/ (Accessed 1 Feb 2014).

10. American Diabetes Association. Living with Diabetes. Hypoglycemia (low blood glucose). Available at http://www.diabetes.org/ (Accessed 1 Feb 2014).

11. NHS Scotland Quality Improvement Hub. Available at http://www. qihub.scot.nhs.uk. (Accessed 1 Feb 2014).

12. ThinkGlucose. Available at http://www.institute.nhs.uk/ quality_and_value/think_glucose/welcome_to_the_website_for_thinkglu cose.html. (Accessed 1 Feb 2014). 